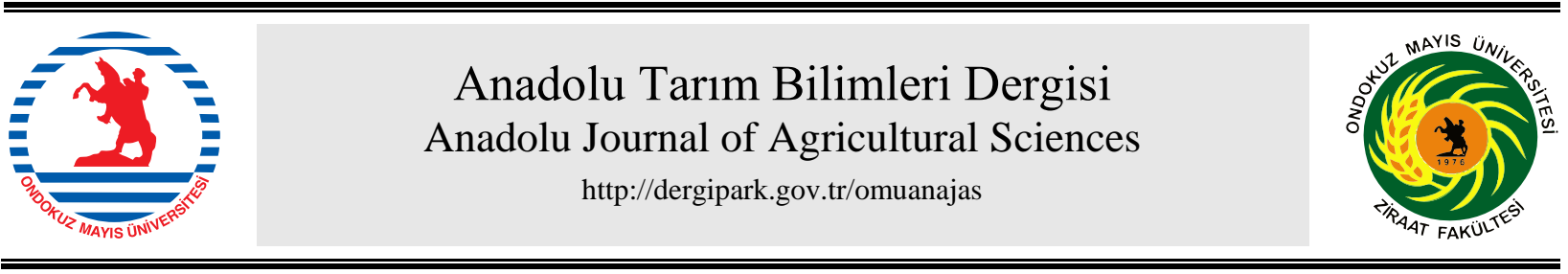

\title{
Araştırma/Research
}

Anadolu Tarım Bilim. Derg./Anadolu J Agr Sci, 34 (2019) ISSN: 1308-8750 (Print) 1308-8769 (Online) doi: 10.7161/omuanajas.558940

\section{Patlıcan anaç 1slahında Solanum melongena ve Solanum aethiopicum genotipleri arasında türler arası melez uyuşumu ve hibrit tohum özellikleri}

\author{
Şeyma Sarıbaş ${ }^{\mathrm{a}}$, Ahmet Balkaya ${ }^{\mathrm{a}}$, Dilek Kandemir ${ }^{\mathrm{b} *}$, Onur Karaağaç ${ }^{\mathrm{c}}$ \\ ${ }^{a}$ Ondokuz Mayıs Üniversitesi Ziraat Fakültesi Bahçe Bitkileri Bölümü, Samsun \\ ${ }^{b}$ Ondokuz Mayls Üniversitesi Samsun Meslek Yüksekokulu Bitkisel ve Hayvansal Üretim Bölümü, Samsun \\ ${ }^{c}$ Tarım ve Kırsal Kalkınmayı Destekleme Kurumu, Amasya \\ "Sorumlu yazar/corresponding author: mdilek@omu.edu.tr
}

Geliş/Received 29/04/2019 Kabul/Accepted 16/06/2019

\begin{abstract}
ÖZET
Aş1lı fide üretiminde anaç seçimi oldukça önemlidir. Anaç olarak, istenilen özelliklere sahip tür içindeki genotipler kullanılabildiği gibi tür içi veya türler arası melez anaçlar da kullanılabilmektedir. Bu çalışmada, yerel patlıcan genotipleri (Solanum melongena) ile yabani patlıcan genotiplerinin (Solanum aethiopicum) türler arası melezlenebilirlik durumları ile bu kombinasyonlara ait meyvelerden elde edilen hibrit tohum özellikleri incelenmiştir. Araştırmada, genetik materyal olarak ülkemizin farklı lokasyonlarından toplanarak karakterizasyonları yapılmış ve uzun süre kendilemeler yapılarak saflaştırılmış durumda bulunan 6 adet yerel patlıcan genotipi (S. melongena) ana ebeveyn ve 10 adet yabani patlıcan genotipi ( $S$. aethiopicum) ise baba ebeveyn olarak kullanılmıştır. İlkbahar ve sonbahar dönemi olmak üzere iki yetiştirme döneminde de, türler arası melez kombinasyonları (S.melongena $\mathrm{x}$ S.aethiopicum) için 30'ar adet melezleme yapılmıştır. Bu melez kombinasyonlarında tutan meyve sayısı ve meyve tutum oranları (\%) belirlenmiştir. Çalışmada, ilkbahar döneminde yapılan melez kombinasyonlarına ait hasat edilen meyvelerin tohumlarında; tohum eni ( $\mathrm{mm})$, boyu ( $\mathrm{mm})$ ve kalınlığı $(\mathrm{mm})$, tohum şekil indeksi, 100 tane ağırlı̆̆ $(\mathrm{g})$, abortif tohum sayısı / meyve (adet), abortif tohum oranı (\%) ve tohum sayısı / meyve (adet) özellikleri incelenmiştir. İki farklı dönemde yapılan melezlemeler sonucunda; ebeveynlere bağlı olarak ortalama meyve tutum oranı \% 47.2 olarak belirlenmiştir. Ana ebeveynlerden SM6 (\% 59) ve SM8 (\%55) ile baba ebeveynlerden SA8 (\% 58), SA6 (\% 55), SA12 (\% 51) ve SA17-1 (\% 50) genotipleri, melez uyuşumu en yüksek genotipler olarak tespit edilmiştir. Meyve başına hibrit tohum sayısı yönünden SM6 x SA6 kombinasyonunda 275 adet ile en yüksek tohum verimi elde edilmiştir. Bu kombinasyonu; SM8 x SA6 (202.17 adet), SM12 x SA6 (200.0 adet) ve SM6 x SA17-2 (116.5 adet) kombinasyonları takip etmiştir. Araştırma sonuçları, hem türler arası melez meyve tutum oranı ve hem de meyve başına elde edilen tohum sayısı yönünden SM8 X SA6, SM6 X SA6, SM12 X SA6 ve SM6 X SA17-2 kombinasyonlarının aşılı patlıcan fidesi üretiminde anaçlık olarak kullanılma potansiyeli bakımından öne çıktığını göstermiştir.
\end{abstract}

Interspecific hybridization and hybrid seed traits of Solanum melongena and Solanum aethiopicum genotypes for eggplant rootstock breeding

\section{ABSTRACT}

Choosing the best rootstock in grafted seedling production is very important. As rootstocks, genotypes within the species with the desired traits can be used, and intraspecific or interspecific hybrid rootstocks can be used. In this study, the hybridization ability of local eggplant genotypes (Solanum melongena) and relative eggplants genotypes (Solanum aethiopicum) and the hybrid seed characteristics obtained from the fruits of these combinations were determined. In this study, genetic materials consisting of 6 local eggplant genotypes ( $S$. melongena) which were collected from different locations of Turkey were used as the female parents and 10 relative eggplant genotypes (S. aethiopicum) were used as the male parents. Both in the spring and autumn periods, 30 hybridizations were made for each interspecific combinations (S. melongena $\mathrm{x}$ S. aethiopicum). The fruit set number and the fruit set percentage $(\%)$
Anahtar Sözcükler: Aşılı fide

Anaç

Melezleme

Tohum

Solanum melongena

Solanum aethiopicum

Keywords: Grafted seedling Rootstock Hybridization Seed Solanum melongena Solanum aethiopicum 
were determined in these hybrid combinations. In the study, seed characteristics (seed width (mm), length $(\mathrm{mm})$ and thickness $(\mathrm{mm})$, seed volume, seed shape index, 100 grain weight $(\mathrm{g})$, abortive seed number / fruit, abortive seed ratio, and number of seeds / fruits) of the spring period combinations' hybrid seeds have been investigated. As a result of hybridization in two different periods; average fruit set percentage was determined as $47.2 \%$ depending on the parents. Crossing compatibility was found to be highest in the female parents of SM $6(59 \%)$, SM8 (55\%) and in the male parents of SA8 (58\%), SA6 (55\%), SA12 (51\%), SA17-1 (50\%) genotypes. In terms of the number of hybrid seeds per fruit, the highest number was obtained from interspecific combination of SM6 x SA6 (275). It was followed by the SM8 x SA6 (202.2), SM12 x SA6 (200.0) and SM6 x SA17-2 (116.5) interspecific combinations. The results showed that the interspecific combinations of SM8 X SA6, SM6 XSA6, SM12 X SA6 and SM6 X SA17-2 were used as rootstock in the production of grafted eggplant seedlings in terms of both cross-species hybrid fruit set ratio and the number of seeds per fruit.

\section{Giris}

Aşı çoğaltım tekniği, her ne kadar meyvecilikle özdeşleştirilmiş olsa da günümüzde sebze fidesi üretiminde de yoğun bir kullanım alanı bulmuştur. Aşılı fide üretimi hem tohum ve hem de aşı ile çoğaltmanın kombine edildiği bilgi, beceri ve teknoloji gerektiren bir tekniktir (Karaağaç, 2013). Sakata ve ark. (2007), aşılı sebze fidesi üretiminde ilk olarak Cucurbita moschata anaçları üzerine karpuzun aşılandığını, daha sonra Lagenaria siceraria ve Benincasa hispida türlerinde aşılama uygulamalarının denendiğini ve 1930'lu yıllardan itibaren Japonya'nın birçok bölgesinde su kabağı üzerine aşılı karpuzun üretimde kullanılmaya başlandığını bildirmişlerdir. Günümüzde sebzelerde aşılama tekniği, özellikle Cucurbitaceae (karpuz, hıyar ve kavun) ve Solanaceae (domates, patlican ve biber) familyası sebzelerinde yaygın olarak uygulanmaktadır. Ülkemizde aşılı fide üretimi, 1998 yılında 70.000 adet ile domatesle başlamıştır. 2001 yılında üretilen 2.5 milyon adet aşılı fidenin 1.5 milyonunu karpuz fidesi oluşturmuştur (Yılmaz ve ark., 2005). Ülkemizde 2015 yılında üretilen aşılı sebze fidelerinin sayısı 175 milyon adede ulaşmıştır. $\mathrm{Bu}$ değerin 77 milyon adedini aşılı karpuz fidesi (\% 44.5) oluşturmaktadır. Bunu yaklaşık 74 milyon adet ile aşılı domates fidesi (\% 42.5) izlemiştir. Bu türleri patlıcan (\%7.5) ve hıyar fideleri $(\%$ 5.3) takip etmektedir (Fidebirlik, 2016). Aşılı fide sektörü çok hızlı bir gelişme göstermesine rağmen, aşılı fide üretiminde kullanılan anaçların çok büyük bir kısmı başka ülkelerden ithal edilmektedir. Ülkemizde aşılı sebze fidesinde kullanılmak üzere yeterli sayıda anaç 1slah programları bulunmamaktadır. $\mathrm{Bu}$ nedenle, ülkemizdeki yerel sebze popülasyonlarının anaç ıslahı programlarında kullanımlarının artırılması ve sürekliliğinin sağlanması büyük bir önem taşımaktadır (Balkaya ve ark., 2015).

Sebze türlerinde aşılamada kullanılan anaçlar niteliklerine göre kalemin erkencilik, verim ve meyve kalitesi ile biyotik ve abiyotik stres koşullarına dayanımları üzerinde etkili olmaktadır. $\mathrm{Bu}$ nedenle aşılı fide üretiminde kullanılacak anaçların seçimi çok önemlidir. Aşılı sebze fidesi üretiminde kullanılacak anaçların tohumları homojen fide çıkışı sağlamalı, hipokotil özellikleri iyi olmalı ve anaç-kalem arasında iyi bir uyuşma göstermelidir (Karaağaç ve Balkaya, 2013; Kandemir ve ark., 2016).
Sebzelerde aşılama ile ilgili ilk çalışmalarda, yabani türler toprak kökenli bazı hastalık, zararlı ve diğer olumsuz koşullara karşı dayanıklı olmaları nedeniyle kültür formlarına anaç olarak kullanılmıştır. Yabani türlerin istenmeyen özelliklerinden kalemin olumsuz etkilenmesi ve yabani formlar ile kültür formları arasında ortaya çıkan uyuşmazlıkların aşılması amacıyla kültür formları ile yabani formlar arasında türler arası melezlemeler yapılarak uygun ticari anaçlar geliştirilmiştir (Balkaya, 2014). Patlıcanda ilk aşı çalışması, 1950'li yıllarda Solanum aethiopicum anacı kullanılarak başlamıştır (Oda, 1999; Iwamoto ve ark., 2007). Patlıcanda aşılı fide kullanılmasının en önemli nedeni; Verticillium solgunluğu, Fusarium solgunluğu, bakteriyel solgunluk ve kök ur nematodları gibi toprak kaynaklı patojenlerin kontrolünün sağlanmasıdır (King ve ark., 2010). Dünyada aşılı patlıcan fidesi üretiminde daha çok Solanum torvum, Solanum incanum $\mathrm{x}$ Solanum melongena ve S. melongena x S. aethiopicum türlerinin melezlenmesi ile elde edilen hibrit çeşitler anaç olarak kullanılmaktadır (Gisbert ve ark., 2011a; Balkaya, 2014). Aşılı patlıcan fidesi üretiminde $S$. torvum türünün anaç olarak; Fusarium solgunluğuna, Verticillium solgunluğuna, bakteriyel solgunluğa ve kök ur nematoduna yüksek düzeyde dayanım sağladığ bildirilmektedir (Yamakawa, 1982; Çürük ve Dayan, 2017). Bununla birlikte, bu türün tohumlarının bir örnek tohum çimlenmesinin olmaması ve hipokotil uzunluğunun çok kısa olması anaç olarak kullanımını sinırlandırmaktadır (King ve ark., 2010). Yapılan çalışmalarda; $S$. aethiopicum ve $S$. incanum gibi patlıcanın yabani formları ile yakın akraba türlerinde toprak kaynaklı hastalık etmenlerine dayanıklılık sağlayan genlerin bulunduğu, buna karşın $S$. melongena türünde dayanıklılık düzeylerinin daha düşük düzeylerde olduğu ortaya konulmuştur (Collonnier ve ark., 2001; Boyac1, 2007; Toppino ve ark., 2008).

Islah programlarında gerçekleştirilen türler arası melezlemelerde; ebeveynlere bağlı olarak (çoğu zaman ya polen tüpü ya da embriyo gelişiminin durması sonucunda) melez başarı oranları yönünden düşük sonuçlar elde edilmektedir (Karaağaç, 2013). Türler arası melezlemede, başarı oranının artması, güçlü ve sağlıklı melez bitkilerin elde edilmesine yönelik olarak öncelikle; melez uyuşumu yüksek genotiplerin seleksiyonu (Whitaker ve Robinson, 1986); embriyo kültürü (İko ve ark., 2003), protoplast füzyonu 
(Tatlioglu, 1993; Yamaguchi ve Shiga, 1993), köprü melezlemeleri (Rhodes, 1959), tomurcuk tozlamas1 (Hayase, 1961; Yongan ve ark., 2002a), tekrarlamalı tozlama (Yongan ve ark., 2002b) ve büyümeyi düzenleyici maddelerin kullanımı (Nascimento ve ark., 2007) gibi birçok uygulamadan yararlanılmaktadır. Bu yöntemlerin içerisinde, anaç ıslah programlarının başarı ile yürütülmesi ve kullanılacak türler arası melez tohumlukların çok sayıda ve pratik bir şekilde başarılı olarak üretilebilmesi için öncelikle birbiriyle karşılıkl uyuşur ebeveyn genotiplerin seleksiyonu daha fazla ön plana çıkmaktadır (Karaağaç ve Balkaya, 2013).

Daunay (2008), S. aethiopicum, S. macrocarpon ve $S$. incanum yabani patlıcan türlerinin, $S$. melongena ile türler arası melezlenmesinde melez başarısının ebeveynlere göre değişkenlik gösterdiğini bildirmiştir. Behera ve Singh (2002), S. melongena ile $S$. aethiopicum türler aras1 melezlemede meyve tutum oranın oldukça fazla olduğunu ve melez meyvelerden elde edilen tohumların canlılık oranlarının da oldukça yüksek olduğunu bildirmişlerdir. Gisbert ve ark. (2011b), S. melongena x S. aethiopicum melezlemesi ile geliştirilmiş türler arası melez anaçlarda yüksek çimlenme (\% 90) ve aşı başarısının (\% 100) elde edildiğini belirlemișlerdir. Araștırıcılar, bu melez kombinasyonunun düzensiz çimlenen $S$. torvum anaç türüne bir alternatif olduğunu ve yeni patlıcan anaçlarının geliştirilmesinde ümit verici melez kombinasyon olduğunu vurgulamışlardır.

Türkiye'de aş1lı patlıcan fidesi üretiminde kullanılmak üzere yerli anaçların 1slahı konusunda yürütülen kapsamlı bir ıslah programı bulunmamaktadır. $\mathrm{Bu}$ nedenle; aşılı patlıcan yetiştiriciliğinde biyotik ve abiyotik stres koşullarına dayanıklı, meyve kalitesini olumsuz yönde etkilemeyen ve verim potansiyelini daha fazla arttırmaya yönelik patlıcan anaçlarının ıslahı ve geliştirilmesine yönelik çalışmaların artırılmasına büyük bir gereksinim vardır. Bu çalışmada, Üniversite Özel Sektör işbirliği kapsamında (San-Tez projesi), Gento Tohumculuk Tarım Sanayi ve Ticaret Ltd. Şti. gen havuzunda bulunan Fusarium solgunluk hastalığına dayanıklı yerel patlican genotipleri (S. melongena) ile ABD USDA Tohum Gen Bankasindan temin edilen ve Fusarium ve Verticillum solgunluk hastalıklarına karşı dayanıklı olarak belirlediğimiz yabani patlıcan genotiplerinin ( $S$. aethiopicum) türler aras1 melezlenebilirlik durumlarının tespit edilerek, melez uyuşumu ve tohum kalitesi yüksek üstün kombinasyonların seleksiyonu amaçlanmıştır.

\section{Materyal ve Yöntem}

\subsection{Materyal}

$\mathrm{Bu}$ çalışma, Ondokuz Mayıs Üniversitesi Ziraat Fakültesi Bahçe Bitkileri Bölümü ile Gento Tohumculuk Tarım Sanayi ve Tic. Ltd. Şti. tarafindan 2015-2016 y1lları arasında Antalya'da firmaya ait ARGE 1slah serasında yürütülmüştür. Denemede, $S$. melongena (SM) x S. aethiopicum (SA) türler aras1 melezleme programı için 6 adet $S$. melongena genotipi (SM3, SM6, SM8, SM9, SM11, SM12) ana ebeveyn ve 10 adet $S$. aethiopicum genotipi (SA3, SA6, SA8, SA11, SA12, SA13, SA14, SA16, SA17-1, SA17-2) ise baba ebeveyn olarak kullanılmıştır. Ana ebeveynler; Gento Tohumculuk firması tarafindan daha önceden morfolojik karakterizasyonu yapılarak genetik yönden saflaştırılmış olan (S5 generasyonunda) ve Fusarium solgunluğuna dayanıklı olarak belirlenen yerel patlıcan genotiplerinden seçilmiştir. Baba ebeveynler ise $\mathrm{ABD}$ USDA Tohum Gen Bankasının patlican gen havuzu içerisinden seçilen, Fusarium ve Verticilium solgunluğuna dayanıklı olduğu belirlenen yabani patlican genotiplerden oluşturulmuştur.

\subsection{Yöntem}

\subsubsection{Patlıcan anaç ıslah programinda yer alan} patlican türlerine ait ebeveynlerin (S. melongena ve $S$. aethiopicum) türler arast melezlenebilirlik durumlarinin belirlenmesi

Çalışmanın ilk aşamasında; S. melongena x $S$. aethiopicum türler arasi melezlerinin elde edilmesi gerçekleştirilmiştir. Melezleme çalışmaları, 2015 yılında Antalya'da ilkbahar ve sonbahar olmak üzere iki farklı dönemde yapılmıştır. Yabani patlıcan ile yerel patlıcan genotiplerinin fideleri, Antalya'da Gento Tohumculuk Tarım Sanayi ve Tic. Ltd. Şti. firmasına ait olan Kayaburnu fide işletmesinde yetiştirilmiştir. Bitkilerin yetiştirilerek melezleme çalışmalarının yapılacağ Kayaburnu fide işletmesinde bulunan patlıcan anaç sslah serasında, toprak işlendikten sonra toprak analiz sonuçlarına göre patlıcan yetiştiriciliği için uygun bir gübreleme ve sulama programı takip edilmiştir. Her genotipten 10 adet olacak şekilde 4-5 gerçek yapraklı fideler seraya dikilmiştir. Gübreleme, ilaçlama vb. kültürel uygulamalara yetiştiricilik süresince düzenli olarak devam edilmiştir.

İlkbahar döneminde melezleme çalışmalarına 24.04.2015 tarihinde başlanmış ve patlıcan genotiplerinin çiçeklenme senkronizasyonuna göre çalışmada yer alan tüm ebeveynler için 40 gün süreyle melezleme işlemlerine devam edilmiş ve 04.06.2015 tarihinde sonlandırılmıştır. Sonbahar döneminde ise melezlemelere 01.10.2015 tarihinde başlanmış, 45 gün süreyle devam edilmiş ve 15.11.2015 tarihinde sonlandırılmıştır. Araştırmada her bir dönemde altı adet anne (S. melongena) ve on adet baba (S. aethiopicum) ebeveyn arasında oluşturulan 60 adet kombinasyonda, (herbir kombinasyon için 30 adet türler arası melezleme olacak şekilde) toplam 1800 adet melezleme yapılmıştır. Melezleme için, önce baba bitkide bulunan çiçekte polenleri yayılmak üzere olan anterler, sapı ile birlikte alınarak steril bir tüpte biriktirilmiştir. Ardından ana bitkide yer alan çiçekte erkek organlar koparıldıktan sonra, baba genotiplerden alınan çiçek tozları, çiçeğin stigmasına firça yardımıyla uygulanmıştır. Türler arası 
melezleme sonrası çiçek, hava geçirgenliği olan bir bez torba ile kapatılıp izole edilerek, dışarıdan yabancı polen girişi engellenmiştir. Melezlemeden 2 gün sonra döllendiği kesinleşen ve irileşmeye başlayan meyvelerden torbalar alınmış ve etiketlenerek kayıt altına alınmıştır. Melezlemeler sonucunda tutan meyve sayısı (adet) ve tutan meyve oranları (\%) belirlenmiştir.

\subsubsection{Patlican anaç islah programındaki} kombinasyonlardan (Solanum melongena x Solanum aethiopicum) hasat edilen meyvelerinin tohum özelliklerinin belirlenmesi

İlkbahar dönemi yapılan melezlemeler sonucunda elde edilen melez meyvelerin tohum özellikleri incelenmiştir. Melez patlıcan meyvelerinde tohum çıkarma işlemi; tohumluk meyvelerin tamamen olgunlaştığ 1 , meyve renklerinin bronz-kahverengi renge dönüştüğü dönemde yapılmıştır. Tohum çıkarma işlemleri için melez meyvelerde hasada 18.06.2015 tarihinde başlanmış ve kademeli olarak 27.07.2015 tarihine kadar devam edilmiştir.

Hasatların tamamlanmasından sonra hibrit tohum elde edilen kombinasyonlarda tohum özellikleri olarak; tohum eni $(\mathrm{mm})$, boyu $(\mathrm{mm})$ ve kalınlığ $(\mathrm{mm})$, tohum şekil indeksi (tohum eninin, tohum boyuna bölünmesiyle elde edilmiştir. Değerin "1" katsayısına yaklaşması yuvarlak şekilli, bu katsayıdan uzaklaşması ise oval şekilli olduğunu göstermektedir), 100 tane ağırlığı (g), abortif tohum sayısı / meyve (adet), abortif tohum oranı (\%) ve tohum sayıs1 / meyve (adet) incelenmiştir. Tohum hacmi (V), Karaağaç ve ark. (2011)'na göre aşağıda verilen 'Eşitlik 1 ve 2' ile hesaplanmıştır.

$$
\begin{aligned}
& V=\frac{\pi B^{2} L^{2}}{6(2 L-B)} \\
& B=(W T)^{0.5} \\
& \text { L: boy; W: en; T: kalınlık }
\end{aligned}
$$

\subsubsection{Verilerin Analizi}

Denemeler; tesadüf parselleri faktöriyel deneme desenine göre (anne $\mathrm{x}$ baba) üç tekerrürlü ve her tekerrürde 5 adet bitki kullanılarak kurulmuştur. \% değerleri içeren kriterlerde öncelikle arcsin transformasyonu yapılmıştır. İstatistiksel olarak önemli bulunan kriterlerde Duncan çoklu karşılaştırma testine göre gruplandırma yapılmıştır.

\section{Bulgular ve Tartışma}

Araştırma sonucunda altı adet anne ( $S$. melongena) ve on adet baba ( $S$. aethiopicum) ebeveyn arasinda yapilan diallel melezlemeler sonucunda 60 adet kombinasyonda (60 adet) değişen oranlarda meyve tutumu gerçekleşmiştir. İki farklı dönemde yapılan melezlemelerde meyve tutum oranı ortalama $\% 47.2$ olarak belirlenmiştir (Çizelge 1). İlkbahar döneminde yapilan melezlemelerde ortalama $\% 43$, sonbahar döneminde ise \% 51 oranında başarı sağlanmıştır. Sonbahar döneminde melezleme başarı oranının daha yüksek olması, sera ortam sıcaklığının ilkbahar dönemine göre daha düşük olmasına bağlanabilir. İstatistiksel değerlendirmelerde hem ana ebeveyn ve hem de baba ebeveynlerin iki farklı dönemdeki melez tutma başarı oranları çok önemli düzeylerde farklılık göstermiş̧tir. Ana ebeveynlerden SM6 ve SM8 genotipleri, sirasiyla ortalama $\% 59$ ve $\% 55$ başarı oranları ile en üst istatistiksel grupta yer almış ve $S$. aethiopicum türü ile en iyi uyuşan genotipler olarak tespit edilmiştir. Ana ebeveynler arasında en düşük melez uyuşum performansı, $\% 30$ oranı ile SM3 genotipinde belirlenmiştir. Baba ebeveynlerde ( $S$. aethiopicum) türler arası melezlemeye en iyi pozitif tepkiyi gösteren genotiplerin sirasıyla SA8 (\% 58), SA6 (\% 55), SA12 (\% 51) ve SA17-1 (\% 50) oldukları tespit edilmiştir. En düşük tozlayıcı baba ebeveyn performansı SA16 (\% 38) genotipinde belirlenmiştir (Çizelge 1). Türler arası melezlemede başarılı meyve tutum oranları yönünden her iki melezleme döneminde de kombinasyonlar incelenmiştir. Genel olarak kombinasyonların büyük bir bölümünde, ilkbahar ve sonbahar dönemlerinde elde edilen melez başarı oranlarının birbirinden farklılık gösterdiği tespit edilmiştir. Bunun nedeni, dönemsel klimatik farklılıklar ve melezleme hatalarından kaynaklanabilir. Bununla birlikte çalş̧mada, türler arası melezleme denemesinde olası deneme farklılıklarına rağmen bazı kombinasyonlarda her iki dönemde de oldukça iyi performanslar elde edilmiştir. Örneğin SM6 ebeveyninin ana olarak kullanıldığı beş farklı kombinasyonda [SM6 x (SA14, SA13, SA8, SA12 ve SA11)], her iki dönemde de ortalama \% 60 - 79 arasında başarı sağlanmıştır. Ana ebeveyn olarak SM6 genotipinin üstün performansını SM8 genotipi takip etmiştir. SM8 genotipinin kullanıldı̆̆ 10 kombinasyonun 7'sinde, her iki dönem ortalaması olarak $\% 55$ 'in üzerinde meyve tutum oranı sağlanmıştır. Türler arası melezlemede başarılı meyve tutum oranı yönünden baba ebeveynlerden SA8 genotipi öne çımış̧ır. Çalışmada; SA8'in baba ve SM6'nın (S: \% 50, İ: \% 100), SM11'in (S: \% 47, İ: \% 80), SM3'ün (S: \% 20, İ: \% 100), SM12'nin (S: \% 57, İ: \% 60) ana olarak kullanıldığ kombinasyonlarda ümit var meyve tutum oranları elde edilmiştir. En yüksek meyve tutum oranı gösteren kombinasyonların; sonbaharda SM9 x SA11 (\% 80), SM6 x SA14 (\% 77), SM11 x SA11 (\% 77) ve ilkbaharda ise SM6 x SA8 (\% 100), SM3 x SA8 (\% 100) oldukları saptanmıştır.

Literatürde S. melongena türü ile en iyi uyuşum gösteren yabani patlican türlerinin; $S$. aethiopicum, $S$. incanum, $S$. macrocarpon ve $S$. Iinneanum olduğu bildirilmiştir (Sihachakr ve ark., 1994; Daunay, 2008). Ali ve Fujieda (1990), S. melongena x $S$. aethiopicum kombinasyonlarında yaptıkları melezlemeler sonucunda meyve tutum oranının \% $13-80$ arasında değiştiğini bildirmişlerdir. Afful ve ark. (2018), farklı ebeveynler ile beş adet $S$. melongena x $S$. aethiopicum kombinasyonunda 655 melezleme işlemi yapmışlar ve meyve tutum 
oranlarının \% 1.3 - 2.7 arasında değişim gösterdiğini tespit etmişlerdir.

Prohens ve ark. (2012), dört adet $S$. melongena x $S$. aethiopicum kombinasyonunda yeterli sayıda meyve eldesi ve hibrit tohum üretimini gerçekleştirmişlerdir. Devi ve ark. (2015), 20 adet $S$. melongena genotipi ile $S$. aethiopicum arasında melezlemeler yapmış, ancak kombinasyonların yarısında meyve tutumu sağlayamamışlardır. Diğer kombinasyonlarda meyve tutum oranları \% 10.0 - \% 75.0 arasında dağılım göstermiştir. Plazas ve ark. (2016), 12 yabani patlıcan türü ile $S$. melongena arasında türler arası melezleme çalışması yapmışlar ve meyve tutum oranlarının \% 0.0 (S. elaeagnifolium, S. sisymbriifolium, S. pyracanthos) ile \% 24.0 (S. dasyphyllum) arasında dağılış gösterdiğini bildirmişlerdir. Bletsos ve ark. (2004), S. melongena x $S$. macrocarpon arasında yaptıkları 246 adet melezleme sonucunda ortalama \% 20.9 meyve tutum oranı elde etmişlerdir. Rao ve Rao (1984), S. melongena ile bazı yabani türler arasında ( $S$. surattense, $S$. indicum, $S$. trilobatum, $S$. torvum) yaptıkları melezlemelerde en yüksek meyve tutum oranını \% 23 ile S. melongena x $S$. torvum kombinasyonundan elde etmişlerdir. Yaptığımız çalışmada elde edilen meyve tutum oranları, literatürde yer alan türler arası melezleme çalışmalarındaki meyve tutum oranları ile kıyaslandığında oldukça yüksek oranlarda melez uyuşum başarısının elde edildiği ortaya çıkmıştır.

Türler arası melez anaç ıslahında meyve başına hibrit tohum sayısı da en önemli seleksiyon kriterlerinden birisidir. Bunun en önemli nedeni meyve tutumu sağlanmış olsa dahi meyvedeki hibrit tohum sayıs1 ve tohum kalitesi yetersiz düzeylerde olabilmesidir. S. melongena (SM) x S. aethiopicum (SA) kombinasyonlarında meyve başına hibrit tohum sayıları (adet), Çizelge 2'de verilmiştir. Meyve başına hibrit tohum sayıları yönünden hem ana ve hem de baba ebeveynler arasında istatistiksel olarak önemli düzeyde farklılıklar olduğu tespit edilmiş̧ir.

Çizelge 1. Türler arası Solanum melongena (SM) x Solanum aethiopicum (SA) kombinasyonlarında tutan meyve oranlarının (\%) değişimi

\begin{tabular}{|c|c|c|c|c|c|c|c|c|}
\hline Dönem & Ana & SM3 & SM6 & SM8 & SM9 & SM11 & SM12 & Baba ort. \\
\hline $\begin{array}{l}\text { SB } \\
\text { İB }\end{array}$ & SA3 & $\begin{array}{l}17 \text { b-f } \\
60 \text { a-f }\end{array}$ & $\begin{array}{l}43 \text { a-f } \\
60 \text { a-f }\end{array}$ & $\begin{array}{l}53 \text { a-f } \\
60 \text { a-f }\end{array}$ & $\begin{array}{l}63 \text { a-f } \\
20 b-f\end{array}$ & $\begin{array}{l}50 \text { a-f } \\
30 \mathrm{~b}-\mathrm{f}\end{array}$ & $\begin{array}{l}67 \text { a-e } \\
10 \text { d-f }\end{array}$ & $45 \mathrm{BC}$ \\
\hline $\begin{array}{l}\text { SB } \\
\text { İB }\end{array}$ & SA6 & $\begin{array}{l}43 \text { a-f } \\
70 \text { a-d }\end{array}$ & $\begin{array}{l}30 \mathrm{~b}-\mathrm{f} \\
50 \mathrm{a}-\mathrm{f}\end{array}$ & $\begin{array}{l}50 \text { a-f } \\
60 \text { a-f }\end{array}$ & $\begin{array}{l}53 a-f \\
80 a b\end{array}$ & $\begin{array}{l}67 \mathrm{a}-\mathrm{e} \\
20 \mathrm{~b}-\mathrm{f}\end{array}$ & $\begin{array}{l}70 \text { a-d } \\
60 \text { a-f }\end{array}$ & $55 \mathrm{AB}$ \\
\hline $\begin{array}{l}\text { SB } \\
\text { İB }\end{array}$ & SA8 & $\begin{array}{l}20 \mathrm{~b}-\mathrm{f} \\
100 \mathrm{a}\end{array}$ & $\begin{array}{l}50 \mathrm{a}-\mathrm{f} \\
100 \mathrm{a}\end{array}$ & $\begin{array}{l}50 \text { a-f } \\
60 \text { a-f }\end{array}$ & $\begin{array}{l}53 \mathrm{a}-\mathrm{f} \\
20 \mathrm{~b}-\mathrm{f}\end{array}$ & $\begin{array}{l}47 \mathrm{a}-\mathrm{f} \\
80 \mathrm{ab}\end{array}$ & $\begin{array}{l}57 \mathrm{a}-\mathrm{f} \\
60 \mathrm{a}-\mathrm{f}\end{array}$ & $58 \mathrm{~A}$ \\
\hline $\begin{array}{l}\text { SB } \\
\text { İB }\end{array}$ & SA11 & $\begin{array}{c}20 \mathrm{~b}-\mathrm{f} \\
0 \mathrm{f}\end{array}$ & $\begin{array}{l}53 \mathrm{a}-\mathrm{f} \\
70 \mathrm{a}-\mathrm{d}\end{array}$ & $\begin{array}{l}43 \mathrm{a}-\mathrm{f} \\
70 \mathrm{a}-\mathrm{d}\end{array}$ & $\begin{array}{l}80 \mathrm{ab} \\
50 \mathrm{a}-\mathrm{f}\end{array}$ & $\begin{array}{l}77 \mathrm{a}-\mathrm{c} \\
30 \mathrm{~b}-\mathrm{f}\end{array}$ & $\begin{array}{l}63 \mathrm{a}-\mathrm{f} \\
20 \mathrm{~b}-\mathrm{f}\end{array}$ & $48 \mathrm{~A}-\mathrm{C}$ \\
\hline $\begin{array}{l}\text { SB } \\
\text { İB }\end{array}$ & SA12 & $\begin{array}{l}13 \mathrm{c}-\mathrm{f} \\
40 \mathrm{a}-\mathrm{f}\end{array}$ & $\begin{array}{l}57 \mathrm{a}-\mathrm{f} \\
80 \mathrm{ab}\end{array}$ & $\begin{array}{l}70 \text { a-d } \\
60 \text { a-f }\end{array}$ & $\begin{array}{l}43 \text { a-f } \\
60 \text { a-f }\end{array}$ & $\begin{array}{l}47 \mathrm{a}-\mathrm{f} \\
40 \mathrm{a}-\mathrm{f}\end{array}$ & $\begin{array}{l}57 \mathrm{a}-\mathrm{f} \\
40 \mathrm{a}-\mathrm{f}\end{array}$ & $51 \mathrm{~A}-\mathrm{C}$ \\
\hline $\begin{array}{l}\text { SB } \\
\text { İB }\end{array}$ & SA13 & $\begin{array}{l}10 \mathrm{~d}-\mathrm{f} \\
20 \mathrm{~b}-\mathrm{f}\end{array}$ & $\begin{array}{l}73 \mathrm{a}-\mathrm{d} \\
80 \mathrm{ab}\end{array}$ & $\begin{array}{l}67 \text { a-e } \\
50 \text { a-f }\end{array}$ & $\begin{array}{l}60 \mathrm{a}-\mathrm{f} \\
30 \mathrm{~b}-\mathrm{f}\end{array}$ & $\begin{array}{c}50 \mathrm{a}-\mathrm{f} \\
0 \mathrm{f}\end{array}$ & $\begin{array}{l}63 \mathrm{a}-\mathrm{f} \\
10 \mathrm{~d}-\mathrm{f}\end{array}$ & $43 \mathrm{BC}$ \\
\hline $\begin{array}{l}\text { SB } \\
\text { İB }\end{array}$ & SA14 & $\begin{array}{c}17 \mathrm{~b}-\mathrm{f} \\
0 \mathrm{f}\end{array}$ & $\begin{array}{l}77 \mathrm{a}-\mathrm{c} \\
80 \mathrm{ab}\end{array}$ & $\begin{array}{l}60 \text { a-f } \\
40 \text { a-f }\end{array}$ & $\begin{array}{l}60 \mathrm{a}-\mathrm{f} \\
10 \mathrm{~d}-\mathrm{f}\end{array}$ & $\begin{array}{l}50 \mathrm{a}-\mathrm{f} \\
20 \mathrm{~b}-\mathrm{f}\end{array}$ & $\begin{array}{l}63 \mathrm{a}-\mathrm{f} \\
40 \mathrm{a}-\mathrm{f}\end{array}$ & $43 \mathrm{BC}$ \\
\hline $\begin{array}{l}\text { SB } \\
\text { İB }\end{array}$ & SA16 & $\begin{array}{c}3 \text { ef } \\
30 \mathrm{~b}-\mathrm{f}\end{array}$ & $\begin{array}{l}43 \mathrm{a}-\mathrm{f} \\
20 \mathrm{~b}-\mathrm{f}\end{array}$ & $\begin{array}{l}50 \mathrm{a}-\mathrm{f} \\
50 \mathrm{a}-\mathrm{f}\end{array}$ & $\begin{array}{l}53 \mathrm{a}-\mathrm{f} \\
40 \mathrm{a}-\mathrm{f}\end{array}$ & $\begin{array}{l}53 \mathrm{a}-\mathrm{f} \\
30 \mathrm{~b}-\mathrm{f}\end{array}$ & $\begin{array}{l}53 \mathrm{a}-\mathrm{f} \\
20 \mathrm{~b}-\mathrm{f}\end{array}$ & $38 \mathrm{C}$ \\
\hline $\begin{array}{l}\text { SB } \\
\text { İB }\end{array}$ & SA17-1 & $\begin{array}{l}37 \mathrm{a}-\mathrm{f} \\
50 \mathrm{a}-\mathrm{f}\end{array}$ & $\begin{array}{l}57 \mathrm{a}-\mathrm{f} \\
50 \mathrm{a}-\mathrm{f}\end{array}$ & $\begin{array}{l}43 \text { a-f } \\
50 \text { a-f }\end{array}$ & $\begin{array}{l}73 \mathrm{a}-\mathrm{d} \\
30 \mathrm{~b}-\mathrm{f}\end{array}$ & $\begin{array}{l}63 \text { a-f } \\
40 \text { a-f }\end{array}$ & $\begin{array}{l}67 \text { a-e } \\
40 \text { a-f }\end{array}$ & $50 \mathrm{~A}-\mathrm{C}$ \\
\hline $\begin{array}{l}\text { SB } \\
\text { İB }\end{array}$ & SA17-2 & $\begin{array}{l}17 \mathrm{~b}-\mathrm{f} \\
40 \mathrm{a}-\mathrm{f}\end{array}$ & $\begin{array}{l}60 \mathrm{a}-\mathrm{f} \\
40 \mathrm{a}-\mathrm{f}\end{array}$ & $\begin{array}{l}47 \text { a-f } \\
60 \text { a-f }\end{array}$ & $\begin{array}{l}63 \mathrm{a}-\mathrm{f} \\
20 \mathrm{~b}-\mathrm{f}\end{array}$ & $\begin{array}{l}57 \mathrm{a}-\mathrm{f} \\
10 \mathrm{~d}-\mathrm{f} \\
\end{array}$ & $\begin{array}{l}73 \text { a-d } \\
40 \mathrm{a}-\mathrm{f}\end{array}$ & $44 \mathrm{BC}$ \\
\hline Ana ort. & & $30 \mathrm{D}$ & $59 \mathrm{~A}$ & $55 \mathrm{AB}$ & $48 \mathrm{BC}$ & $43 \mathrm{C}$ & $49 \mathrm{BC}$ & 47.2 \\
\hline Dönem & & Sonbahar: & & & İlkba & $43 \mathrm{~B}$ & & \\
\hline
\end{tabular}


Çizelge 2. Solanum melongena (SM) x Solanum aethiopicum (SA) kombinasyonlarında meyve başına hibrit tohum sayıları (adet)

\begin{tabular}{rcccccc|l}
\hline Ana & SM3 & SM6 & SM8 & SM9 & SM11 & SM12 & \multicolumn{1}{l}{ Baba ort. } \\
\hline SA3 & $2.00 \mathrm{fg}$ & $1.50 \mathrm{fg}$ & $29.00 \mathrm{~d}-\mathrm{g}$ & $0.50 \mathrm{~g}$ & $0.00 \mathrm{~g}$ & $0.00 \mathrm{~g}$ & $5.50 \mathrm{C}$ \\
SA6 & $45.86 \mathrm{c-g}$ & $\mathbf{2 7 5 . 0 0 ~ a}$ & $\mathbf{2 0 2 . 1 7} \mathbf{~ b}$ & $0.00 \mathrm{~g}$ & $64.00 \mathrm{c}-\mathrm{g}$ & $\mathbf{2 0 0 . 0 0 ~ b}$ & $131.17 \mathrm{~A}$ \\
SA8 & $3.50 \mathrm{e}-\mathrm{g}$ & $29.40 \mathrm{~d}-\mathrm{g}$ & $14.75 \mathrm{~d}-\mathrm{g}$ & $0.00 \mathrm{~g}$ & $0.00 \mathrm{~g}$ & $40.00 \mathrm{~d}-\mathrm{g}$ & $14.61 \mathrm{BC}$ \\
SA11 & $0.00 \mathrm{~g}$ & $0.00 \mathrm{~g}$ & $28.00 \mathrm{~d}-\mathrm{g}$ & $0.00 \mathrm{~g}$ & $1.33 \mathrm{fg}$ & $8.50 \mathrm{~d}-\mathrm{g}$ & $6.31 \mathrm{C}$ \\
SA12 & $0.00 \mathrm{~g}$ & $0.33 \mathrm{~g}$ & $1.80 \mathrm{f}-\mathrm{g}$ & $1.00 \mathrm{fg}$ & $0.00 \mathrm{~g}$ & $0.00 \mathrm{~g}$ & $0.52 \mathrm{C}$ \\
SA13 & $4.00 \mathrm{e}-\mathrm{g}$ & $0.25 \mathrm{~g}$ & $3.29 \mathrm{e}-\mathrm{g}$ & $15.33 \mathrm{~d}-\mathrm{g}$ & $0.00 \mathrm{~g}$ & $0.00 \mathrm{~g}$ & $3.81 \mathrm{C}$ \\
SA14 & $0.00 \mathrm{~g}$ & $29.86 \mathrm{~d}-\mathrm{g}$ & $71.50 \mathrm{c}-\mathrm{f}$ & $0.00 \mathrm{~g}$ & $0.00 \mathrm{~g}$ & $17.00 \mathrm{~d}-\mathrm{g}$ & $19.89 \mathrm{BC}$ \\
SA16 & $1.00 \mathrm{~g}$ & $0.33 \mathrm{~g}$ & $0.00 \mathrm{~g}$ & $0.00 \mathrm{~g}$ & $0.00 \mathrm{~g}$ & $0.00 \mathrm{~g}$ & $0.06 \mathrm{C}$ \\
SA17-1 & $9.75 \mathrm{~d}-\mathrm{g}$ & $4.00 \mathrm{e}-\mathrm{g}$ & $73.75 \mathrm{c}-\mathrm{e}$ & $1.00 \mathrm{fg}$ & $77.50 \mathrm{~cd}$ & $44.00 \mathrm{~d}-\mathrm{g}$ & $35.00 \mathrm{~B}$ \\
SA17-2 & $34.75 \mathrm{~d}-\mathrm{g}$ & $\mathbf{1 1 6 . 5 0 ~ \mathbf { ~ }}$ & $0.00 \mathrm{~g}$ & $0.50 \mathrm{~g}$ & $0.00 \mathrm{~g}$ & $20.00 \mathrm{~d}-\mathrm{g}$ & $28.63 \mathrm{~B}$ \\
\hline Ana ort. & $10.09 \mathrm{~B}$ & $45.72 \mathrm{~A}$ & $42.43 \mathrm{~A}$ & $1.83 \mathrm{~B}$ & $14.28 \mathrm{~B}$ & $32.95 \mathrm{~A}$ & 24.55 \\
\hline
\end{tabular}

Ana: $\mathrm{P}<0.01$, Baba: $\mathrm{P}<0.01$, Ana x Baba: $\mathrm{P}<0.01, \mathrm{CV}(\%): 24$

Aynı zamanda ana $\mathrm{x}$ baba interaksiyonu da istatistiksel olarak önemli bulunmuştur. Çalışma sonucunda incelenen 60 adet kombinasyondan ortalama 24.55 adet hibrit tohum elde edilmiştir. SM6, SM8 ve SM12 genotiplerinin ana ebeveyn olarak kullanıldıkları kombinasyonlardan sirasiyla ortalama 45.72, 42.43 ve 32.95 adet tohum elde edilmiştir. Araştırmada, uyuşmazlık seviyesi en yüksek olan ana ebeveyn ortalama meyve başina 1.83 adet tohum eldesi ile SM9 genotipi olmuştur. Baba ebeveynler içerisinden SA6'nın kullanıldığ 1 kombinasyonlarda ise ortalama 131.17 adet tohum alınmıştır. SA6 baba ebeveyni yüksek tohum verimi ile üst grupta tek başına yer almıştır. Diğer baba ebeveynlerin tohum saylları ise ortalama 0.06 (SA16) 35.0 (SA17-1) adet arasında dağılım göstermiş̧tir. Ortalama meyve başına hibrit tohum sayısı yönünden SM6 x SA6 kombinasyonunda 275 adet ile en yüksek tohum verimi elde edilmiştir. Bu kombinasyonu; SM8 x SA6 (202.17 adet), SM12 x SA6 (200.0 adet) ve SM6 x SA17-2 (116.5 adet) kombinasyonları takip etmiştir.

Afful ve ark. (2018), meyve tutumunun sağlandığ $S$. melongena $\mathrm{x}$ S. aethiopicum kombinasyonlarında meyve başına 0 - 202 adet arasında değişen sayılarda tohum elde etmişlerdir. Bu değerleri, Ali ve Fujieda (1990), ortalama 25 adet ve Devi ve ark. (2015) ise 0 - 106.7 arasında bulmuşlardır. S. melongena x $S$. macrocarpon kombinasyonunda meyve başına tohum sayısının 67 adet (Oyelana ve Ugborogho, 2008), S. melongena x $S$. torvum melezinde 58 - 83 adet (Kumchai ve ark., 2013) ve $S$. melongena x $S$. elaeagnifolium kombinasyonunda ise ortalama 12.2 adet (García-Fortea ve ark., 2019) olduğu tespit edilmiştir. $\mathrm{Bu}$ çalışmada, 60 adet kombinasyonun tamamindan meyve elde edilmesine rağmen 22 tanesinin meyvesinden hiç tohum alınamamıştır. $\mathrm{Bu}$ durum, meyve tutum oranından ziyade meyvedeki tohum sayısının çok daha önemli bir kriter olduğunu göstermektedir. Nitekim SM6 x SA13 kombinasyonunda meyve tutma oranı ortalama \% 77 oranında olmasına rağmen meyve başına tohum sayısının sadece 0.25 adet olduğu tespit edilmiştir.

Türler aras1 melez kombinasyonlarına ait tohum boyutları incelendiğinde belirgin düzeyde farklılıkların olduğu saptanmıştır. En uzun tohumlar, SM3'ün ana ebeveyn olarak kullanıldığ $\breve{1}_{\text {kombinasyonlarda }}$ ölçülmüştür (Çizelge 3). SM3 x SA16 (4.52 mm), SM3 x SA17-1 (4.39 mm), SM3 x SA8 (4.25 mm), SM3 x SA13 $(4.19 \mathrm{~mm})$ ve $\mathrm{SM} 3 \quad \mathrm{x}$ SA6 $(4.17 \mathrm{~mm})$ kombinasyonlarına ait tohumlar daha uzun ve aynı istatistiksel grupta yer almışlardır. En kısa tohumlar ise SM6 x SA13 $(3.01 \mathrm{~mm})$ ve SM8 x SA6 $(3.03 \mathrm{~mm})$ kombinasyonlarında ölçülmüştür. Kombinasyonlara ait tohum eni değerleri, $2.73 \mathrm{~mm}-3.95 \mathrm{~mm}$ arasında dağılış göstermiştir. SM9 genotipinin ana olarak kullanıldığ1 kombinasyonlara ait tohumların enleri en dar (ortalama $2.95 \mathrm{~mm}$ ) ve SM3'ün ana olarak kullanıldığı kombinasyonlarda ise tohum enleri en geniş (ortalama $3.65 \mathrm{~mm}$ ) grubu oluşturmuşlardır. Tohum kalınlık değerleri yönünden en yüksek değer; $1.23 \mathrm{~mm}$ ile SM9 x SA12 ve SM9 x SA17-2 kombinasyonlarında ölçülmüştür. En ince tohumlar ise SM11 x SA6 (0.79 $\mathrm{mm})$, SM6 x SA16 $(0.80 \mathrm{~mm})$ ve SM6 x SA6 $(0.80$ $\mathrm{mm})$ kombinasyonlarında tespit edilmiştir. Genel olarak en kalın tohumlar SM9, en ince tohumlar ise SM12'nin ana olarak kullanıldığı kombinasyonlarda saptanmıştır. Tohum hacim özellikleri yönünden en yüksek değerler; sirasiyla SM3 x SA16 $\left(5.46 \mathrm{~mm}^{3}\right)$, SM3 x SA17-2 (5.42 $\left.\mathrm{mm}^{3}\right)$ ve SM3 x SA17-1 (5.33 $\left.\mathrm{mm}^{3}\right)$ kombinasyonlarında belirlenmiştir. Ayrıca SM8 x SA6 $\left(2.98 \mathrm{~mm}^{3}\right)$ SM6 x SA16 $\left(3.00 \mathrm{~mm}^{3}\right)$ ve SM8 x SA14 $\left(3.02 \mathrm{~mm}^{3}\right)$ en düşük hacimli tohumları içeren 
kombinasyonlar olarak belirlenmiştir. Araştırma sonucunda en iri tohumlar, ortalama $5.07 \mathrm{~mm}^{3}$ hacimle SM3, en küçük tohumlar ise SM8 $\left(3.78 \mathrm{~mm}^{3}\right)$ ') in ana olarak kullanıldığı kombinasyonlarda tespit edilmiştir (Çizelge 3).

Çizelge 3. Türler arası patlıcan (S. melongena (SM) x Solanum aethiopicum (SA)) melez kombinasyonlarının tohum boyutları ve hacimleri yönünden değişimleri

\begin{tabular}{|c|c|c|c|c|}
\hline Kombinasyonlar & $\begin{array}{l}\text { Tohum boyu } \\
\text { (mm) }\end{array}$ & $\begin{array}{l}\text { Tohum eni } \\
\text { (mm) }\end{array}$ & $\begin{array}{l}\text { Tohum kalınlığ } 1 \\
(\mathrm{~mm})\end{array}$ & $\begin{array}{c}\text { Tohum hacmi } \\
\left(\mathrm{mm}^{3}\right)\end{array}$ \\
\hline SM3 x SA3 & $3.77 \mathrm{e}-\mathrm{j}$ & $3.20 \mathrm{~d}-\mathrm{j}$ & $1.12 \mathrm{a}-\mathrm{d}$ & $4.72 \mathrm{a}-\mathrm{g}$ \\
\hline SM3 x SA6 & $4.17 \mathrm{a}-\mathrm{d}$ & $3.50 \mathrm{~b}-\mathrm{d}$ & $0.93 \mathrm{~h}-\mathrm{k}$ & $4.53 \mathrm{~b}-\mathrm{h}$ \\
\hline SM3 x SA8 & $4.25 \mathrm{a}-\mathrm{c}$ & $3.95 \mathrm{a}$ & $0.91 \mathrm{i}-1$ & $5.15 \mathrm{a}-\mathrm{c}$ \\
\hline SM3 x SA13 & $4.19 \mathrm{a}-\mathrm{d}$ & $3.57 \mathrm{bc}$ & $0.97 \mathrm{f}-\mathrm{k}$ & 4.88 a-e \\
\hline SM3 x SA16 & $4.52 \mathrm{a}$ & $3.79 \mathrm{ab}$ & $0.96 \mathrm{f}-\mathrm{k}$ & $5.46 \mathrm{a}$ \\
\hline SM3 x SA17-1 & $4.39 \mathrm{ab}$ & $3.78 \mathrm{ab}$ & $0.96 \mathrm{f}-\mathrm{k}$ & $5.33 \mathrm{ab}$ \\
\hline SM3 x SA17-2 & $4.06 \mathrm{~b}-\mathrm{e}$ & $3.75 \mathrm{ab}$ & $1.03 \mathrm{c}-\mathrm{h}$ & $5.42 \mathrm{a}$ \\
\hline SM6 x SA3 & $4.00 \mathrm{c}-\mathrm{f}$ & $3.34 \mathrm{c}-\mathrm{i}$ & $0.96 \mathrm{f}-\mathrm{k}$ & $4.33 \mathrm{c}-\mathrm{j}$ \\
\hline SM6 x SA6 & 3.77 e-j & $3.06 \mathrm{~g}-1$ & $0.80 \mathrm{~lm}$ & $3.05 \mathrm{~lm}$ \\
\hline SM6 x SA8 & $3.59 \mathrm{i}-\mathrm{k}$ & $2.99 \mathrm{j}-1$ & $0.93 \mathrm{~h}-\mathrm{k}$ & $3.40 \mathrm{k}-\mathrm{m}$ \\
\hline SM6 x SA12 & $3.98 \mathrm{c}-\mathrm{g}$ & $3.41 \mathrm{c}-\mathrm{f}$ & $1.06 \mathrm{~b}-\mathrm{f}$ & 4.95 a-e \\
\hline SM6 x SA13 & 3.011 & $3.07 \mathrm{~g}-\mathrm{k}$ & $1.05 \mathrm{~b}-\mathrm{g}$ & $3.62 \mathrm{i}-\mathrm{m}$ \\
\hline SM6 x SA14 & $4.00 \mathrm{c}-\mathrm{f}$ & $3.29 \mathrm{c}-\mathrm{j}$ & $1.09 \mathrm{~b}-\mathrm{e}$ & $4.92 \mathrm{a}-\mathrm{e}$ \\
\hline SM6 x SA16 & $3.73 \mathrm{e}-\mathrm{j}$ & $3.04 \mathrm{~h}-1$ & $0.80 \mathrm{~lm}$ & $3.00 \mathrm{~m}$ \\
\hline SM6 x SA17-1 & $3.84 \mathrm{~d}-\mathrm{i}$ & $3.30 c-j$ & $1.02 \mathrm{c}-\mathrm{i}$ & $4.45 \mathrm{c}-\mathrm{i}$ \\
\hline SM6 x SA17-2 & 3.75 e-j & $3.02 \mathrm{~h}-1$ & $0.97 \mathrm{f}-\mathrm{k}$ & 3.73 h-m \\
\hline SM8 x SA3 & $3.67 \mathrm{f}-\mathrm{j}$ & $3.19 \mathrm{~d}-\mathrm{j}$ & $0.95 \mathrm{f}-\mathrm{k}$ & 3.82 h-m \\
\hline SM8 x SA6 & 3.031 & 2.731 & $1.00 \mathrm{e}-\mathrm{j}$ & $2.98 \mathrm{~m}$ \\
\hline SM8 x SA8 & $3.86 \mathrm{~d}-\mathrm{i}$ & $3.38 \mathrm{c}-\mathrm{g}$ & $0.98 \mathrm{e}-\mathrm{k}$ & $4.38 \mathrm{c}-\mathrm{i}$ \\
\hline SM8 x SA11 & 3.70 e-j & $3.20 \mathrm{~d}-\mathrm{j}$ & $0.96 \mathrm{f}-\mathrm{k}$ & $3.90 \mathrm{~g}-\mathrm{k}$ \\
\hline SM8 x SA12 & $3.53 \mathrm{i}-\mathrm{k}$ & $3.28 c-j$ & 0.99 e-j & $4.03 \mathrm{f}-\mathrm{k}$ \\
\hline SM8 x SA13 & $3.54 \mathrm{i}-\mathrm{k}$ & $3.15 e-j$ & $0.96 \mathrm{f}-\mathrm{k}$ & 3.72 h-m \\
\hline SM8 x SA14 & $3.29 \mathrm{k}$ & $2.81 \mathrm{kl}$ & $0.94 \mathrm{~g}-\mathrm{k}$ & $3.02 \mathrm{~m}$ \\
\hline SM8 x SA17-1 & $3.82 \mathrm{~d}-\mathrm{j}$ & $3.17 \mathrm{~d}-\mathrm{j}$ & $1.05 \mathrm{~b}-\mathrm{g}$ & $4.37 \mathrm{c}-\mathrm{i}$ \\
\hline SM9 x SA3 & $4.05 \mathrm{~b}-\mathrm{e}$ & $3.03 \mathrm{~h}-1$ & $1.16 \mathrm{ab}$ & $4.85 \mathrm{a}-\mathrm{f}$ \\
\hline SM9 x SA12 & $3.59 \mathrm{i}-\mathrm{k}$ & $3.03 \mathrm{~h}-1$ & $1.23 \mathrm{a}$ & $4.79 \mathrm{a}-\mathrm{f}$ \\
\hline SM9 x SA13 & $3.46 \mathrm{jk}$ & $2.80 \mathrm{kl}$ & $1.01 \mathrm{c}-\mathrm{j}$ & $3.38 \mathrm{k}-\mathrm{m}$ \\
\hline SM9 x SA17-1 & $3.72 e-j$ & $2.78 \mathrm{kl}$ & $1.13 \mathrm{a}-\mathrm{c}$ & $4.02 \mathrm{f}-\mathrm{k}$ \\
\hline SM9 x SA17-2 & $3.67 \mathrm{f}-\mathrm{j}$ & $3.11 \mathrm{f}-\mathrm{k}$ & $1.23 \mathrm{a}$ & $5.01 \mathrm{a}-\mathrm{d}$ \\
\hline SM11 x SA6 & $3.78 \mathrm{e}-\mathrm{j}$ & $3.41 \mathrm{c}-\mathrm{f}$ & $0.79 \mathrm{~m}$ & $3.41 \mathrm{k}-\mathrm{m}$ \\
\hline SM11 x SA11 & $4.01 \mathrm{c}-\mathrm{f}$ & $3.26 \mathrm{c}-\mathrm{j}$ & $0.96 \mathrm{f}-\mathrm{k}$ & $4.22 \mathrm{~d}-\mathrm{k}$ \\
\hline SM11 x SA17-1 & $3.77 \mathrm{e}-\mathrm{j}$ & $3.35 \mathrm{c}-\mathrm{h}$ & $1.03 \mathrm{c}-\mathrm{h}$ & $4.52 \mathrm{~b}-\mathrm{h}$ \\
\hline SM12 x SA6 & $3.49 \mathrm{i}-\mathrm{k}$ & $3.01 \mathrm{i}-1$ & $0.96 \mathrm{f}-\mathrm{k}$ & $3.49 \mathrm{j}-\mathrm{m}$ \\
\hline SM12 x SA8 & $3.97 \mathrm{c}-\mathrm{h}$ & $3.46 \mathrm{~b}-\mathrm{e}$ & $0.89 \mathrm{j}-\mathrm{m}$ & $4.11 \mathrm{e}-\mathrm{k}$ \\
\hline SM12 x SA11 & $3.85 \mathrm{~d}-\mathrm{i}$ & $3.41 \mathrm{c}-\mathrm{f}$ & $0.94 \mathrm{~g}-\mathrm{k}$ & $4.21 \mathrm{~d}-\mathrm{k}$ \\
\hline SM12 x SA14 & $3.60 \mathrm{~h}-\mathrm{k}$ & $3.22 \mathrm{~d}-\mathrm{j}$ & $0.94 \mathrm{~g}-\mathrm{k}$ & 3.76 h-m \\
\hline SM12 x SA17-1 & $3.70 \mathrm{e}-\mathrm{j}$ & $3.26 c-j$ & 0.94 g-k & $3.89 \mathrm{~g}-1$ \\
\hline SM12 x SA17-2 & $3.61 \mathrm{~g}-1$ & $3.23 \mathrm{~d}-\mathrm{j}$ & $0.87 \mathrm{k}-\mathrm{m}$ & $3.46 \mathrm{k}-\mathrm{m}$ \\
\hline $\mathrm{P}$ & 0.01 & 0.01 & 0.01 & 0.01 \\
\hline $\mathrm{CV}(\%)$ & 2.3 & 2.5 & 3.0 & 4.8 \\
\hline
\end{tabular}


İncelenen kombinasyonların tohum şekil indeksleri, 1.08 (SM3 x SA17-2, SM8 x SA12) ile 1.34 (SM9 x SA3, SM9 x SA17-1) arasında değişim göstermiştir. SM8 ve SM12'nin bulunduğu kombinasyonlara ait tohumlar yuvarlağa yakın iken SM9'un ebeveyn olarak kullanıldığı kombinasyonlara ait tohumların ise daha oval olduğu saptanmıștır. Birim tohum ağırlığının fazla olması endosperm hacminin fazlalığıyla direkt ilişkilidir (Bremner ve ark., 1963). Bu nedenle birim ağırlığı fazla olan tohumların olumsuz ortam koşullarına karşı tohum gücü değerleri daha fazla olmaktadır. Ayrıca bu durum elde edilecek fidenin güçlü olmasına da katkı sağlamaktadır. En yüksek 100 tane ağırlığı SM9 x SA17-2 kombinasyonunda $1.17 \mathrm{~g}$ olarak belirlenmiş ve tek başına istatistiksel grup oluşturmuştur. $\mathrm{Bu}$ kombinasyonu; SM9 x SA3 (1.00 g) ve SM3 x SA17-1 $(0.92 \mathrm{~g})$ kombinasyonları izlemiştir. SM6 x SA12 kombinasyonu ise $0.34 \mathrm{~g}$ ile 100 tane ağırlığı yönünden en son sırada yer almıştır. Genel olarak SM3 ve SM9 genotipinin kullanıldığg melez kombinasyonlarında 100 tane ağırlığı daha yüksek, SM12'nin ebeveyn olarak kullanıldığı kombinasyonlarda bu değerin daha düşük olduğu bulunmuştur (Çizelge 4). Daunay ve ark. (1993), $S$. melongena $\mathrm{x} S$. aethiopicum kombinasyonundaki meyve başına tohum ağırlıklarının $0.3-0.95 \mathrm{~g}$ arasında değiştiğini belirlemişlerdir. Plazas ve ark. (2016), 12 yabani patlıcan türü ile $S$. melongena arasında yaptıkları melezleme çalışmalarında; meyve başına tohum ağırlıklarının $0.09 \mathrm{~g}$ (S. violaceum) ile $2.67 \mathrm{~g}$ (S. insanum) arasında dağılış gösterdiğini bildirmişlerdir. Çalışma sonuçları, 100 tane ağırlıkları yüksek bulunan kombinasyonlarda tohum sayısının oldukça düşük sayılarda olduğunu göstermektedir. 100 tohum ağırlığı yönünden ilk siralarda yer alan kombinasyonların tohum sayıları sirasiyla 0.50 (SM9 x SA17-2), 0.50 (SM9 x SA3) ve 9.75 (SM3 x SA17-1) adet olarak bulunmuştur (Çizelge 2). Bu nedenle meyve başına tohum sayısı fazla olan kombinasyonlar içerisinde 100 tane ağırlıklarının da kıyaslanması yararlı olacaktır. Tohum sayı1S1 yönünden öne çıkan SM6 x SA6 (275.0 adet), SM8 x SA6 (202.17 adet), SM12 x SA6 (200.0 adet) ve SM6 x SA17-2 (116.5 adet) kombinasyonlarını 100 tane ağırlıkları sırasıyla $0.38 \mathrm{~g}, 0.45 \mathrm{~g}, 0.43 \mathrm{~g}$ ve $0.59 \mathrm{~g}$ olarak tespit edilmiştir. Belirtilen bu iki özellik bir arada değerlendirildiğinde; SM8 x SA6 kombinasyonu ön plana çıkmaktadır.

Türler arası melez anaç ıslahında diğer bir seleksiyon kriteri ise meyvede oluşan tohumlardaki abortif tohum oranıdır. Çalışmada 60 kombinasyon içerisinde tohum alınabilen 38 kombinasyonda ortalama \% 4.4 abortif tohum oluşumunun meydana geldiği saptanmıştır. Kombinasyonların 17'sinde abortif tohum meydana gelmemiştir. Kullanılan ana ebeveyne göre abortif tohum oranı incelendiğinde, en düşük oran SM9 (\% 0.97) ve en yüksek oran ise SM3 (\% 12.75) genotipinin kullanıldığı kombinasyonlarda tespit edilmiştir. En yüksek abortif tohum oluşumu SM3 x SA16 (\% 33.33), SM6 x SA3 (\% 22.22) ve SM3 x SA8
(\% 21.43) kombinasyonlarında saptanmıştır. Ayrıca abortif tohum oranı yüksek olan kombinasyonların tamamına yakınında tohum sayısı değerlerinin de düşük sayılarda olduğu bulunmuştur. Tohum sayısı değerleri yönünden öne çıkan SM6 x SA6, SM8 x SA6, SM12 x SA6 ve SM6 x SA17-2 kombinasyonlarında abortif tohum oluşumu değerleri sirasıyla \% 7.27, \% 1.07, \% 1.67 ve \% 1.29 olarak hesaplanmıştır.

Literatürde $S$. melongena ile $S$. aethiopicum türleri, kendi aralarında uyuşur türler olarak bilinmelerine rağmen partenokarpik meyve ve çok az tohum oluşumunun da meydana geldiği bildirilmiştir (Collonnier ve ark., 2001; Calvo-Asensio ve ark., 2014). Devi ve ark. (2015), S. melongena x S. aethiopicum kombinasyonlarında ve Prohens ve ark. (2012), $S$. melongena $\mathrm{x} S$. aethiopicum genotiplerinin geriye melezlenmesi aşamasında yüksek seviyede partenokarpik meyve oluşumlarının meydana geldiğini belirtmişlerdir. Buna rağmen; Ali ve Fujieda (1990), bu kombinasyonlarda abortif tohum oluşumunun olmadığını bildirmişlerdir. Literatürdeki bu farklılık, kullanılan ebeveynlerin, tercih edilen kombinasyonların ve çevresel klimatik faktörlerin benzer olmamalarından kaynaklanmış olabilir.

\section{Sonuç}

Ülkemizde aşılı fide üretim teknolojisinde son yıllarda önemli gelişmeler olmasına rağmen, aşılı fide üretiminde kullanılan anaç çeşit 1slahı konusunda yeterli sayıda 1slah çalışması bulunmamaktadır. Anaç ıslah çalışmalarında yabani türler bazı üstün dayanıklılık özellikleri yönünden önemli varyasyon kaynağıdır ve bu yönden anaç çeşit ıslah programlarında çok fazla tercih edilmektedir. Patlıcan için türler arası melezlemedeki başarı derecesi, kullanılan yabani türlere ve $S$. melongena genotiplerine bağlı olarak değişkenlik göstermektedir.

Bu çalışmada 6 adet ana (S. melongena) ile 10 adet baba (S. aethiopicum) ebeveyn kullanılarak oluşturulan kombinasyonlarda (60 kombinasyon) ilkbahar ve sonbahar dönemlerinde 1800 'er adet olmak üzere toplam 3600 melezleme yapılmıştır. Melezlenebilirlik yönünden İki farklı dönemde yapılan melezlemelerde meyve tutum oranı ortalama \% 47.2 olarak belirlenmiştir. En yüksek meyve tutum oranı gösteren kombinasyonların; sonbaharda SM9 x SA11 (\% 80), SM6 x SA14 (\% 77), SM11 x SA11 (\% 77) ve ilkbaharda ise SM6 x SA8 (\% 100), SM3 x SA8 (\% 100) oldukları saptanmıştır. İlkbahar döneminde meyve başına hibrit tohum sayıları yüksek olan SM6 x SA6 (275 adet), SM8 x SA6 (202.17 adet), SM12 x SA6 $(200$ adet) ve SM6 x SA17-2 (116.5 adet) kombinasyonlarında ilkbahar dönemindeki meyve tutum oranlarının sirasıyla \% 50, \% 60, \% 60 ve \% 40 olduğu tespit edilmiştir. 
Çizelge 4. Türler arası patlıcan melez kombinasyonlarının bazı tohum özellikleri

\begin{tabular}{|c|c|c|c|}
\hline Kombinasyonlar & Tohum şekil indeksi & $\begin{array}{l}100 \text { tane ağırlığ } 1 \\
(\mathrm{~g})\end{array}$ & $\begin{array}{c}\text { Abortif tohum oran1 } \\
(\%)\end{array}$ \\
\hline SM3 x SA3 & $1.18 \mathrm{~b}-\mathrm{h}$ & $0.75 \mathrm{c}-\mathrm{h}$ & $0.00 \mathrm{f}$ \\
\hline SM3 x SA6 & $1.19 \mathrm{~b}-\mathrm{g}$ & $0.58 \mathrm{~g}-\mathrm{m}$ & $16.20 \mathrm{~b}-\mathrm{d}$ \\
\hline SM3 x SA8 & $1.13 \mathrm{~g}-\mathrm{j}$ & $0.82 \mathrm{~b}-\mathrm{e}$ & $21.43 \mathrm{bc}$ \\
\hline SM3 x SA13 & $1.17 \mathrm{c}-\mathrm{i}$ & $0.86 \mathrm{~b}-\mathrm{d}$ & $12.50 \mathrm{c}-\mathrm{e}$ \\
\hline SM3 x SA16 & $1.19 \mathrm{~b}-\mathrm{g}$ & $0.79 \mathrm{c}-\mathrm{f}$ & $33.33 \mathrm{a}$ \\
\hline SM3 x SA17-1 & $1.16 \mathrm{~d}-\mathrm{i}$ & $0.92 \mathrm{bc}$ & $0.00 \mathrm{f}$ \\
\hline SM3 x SA17-2 & $1.08 \mathrm{j}$ & $0.78 \mathrm{c}-\mathrm{g}$ & $5.76 \mathrm{ef}$ \\
\hline SM6 x SA3 & $1.20 \mathrm{~b}-\mathrm{f}$ & $0.57 \mathrm{~h}-\mathrm{m}$ & $22.22 \mathrm{~b}$ \\
\hline SM6 x SA6 & $1.23 \mathrm{bc}$ & $0.38 \mathrm{mn}$ & $7.27 \mathrm{~d}-\mathrm{f}$ \\
\hline SM6 x SA8 & $1.20 \mathrm{~b}-\mathrm{f}$ & $0.58 \mathrm{~g}-\mathrm{m}$ & $0.68 \mathrm{f}$ \\
\hline SM6 x SA12 & $1.17 \mathrm{c}-\mathrm{i}$ & $0.34 \mathrm{n}$ & $0.00 \mathrm{f}$ \\
\hline SM6 x SA13 & $1.18 \mathrm{~b}-\mathrm{h}$ & $0.50 \mathrm{i}-\mathrm{n}$ & $0.00 \mathrm{f}$ \\
\hline SM6 x SA14 & $1.22 \mathrm{~b}-\mathrm{d}$ & $0.53 \mathrm{i}-\mathrm{n}$ & $0.48 \mathrm{f}$ \\
\hline SM6 x SA16 & $1.23 \mathrm{bc}$ & $0.54 \mathrm{i}-\mathrm{n}$ & $0.00 \mathrm{f}$ \\
\hline SM6 x SA17-1 & $1.16 \mathrm{~d}-\mathrm{i}$ & $0.56 \mathrm{~h}-\mathrm{m}$ & $0.00 \mathrm{f}$ \\
\hline SM6 x SA17-2 & $1.24 \mathrm{~b}$ & $0.59 \mathrm{f}-1$ & $1.29 \mathrm{f}$ \\
\hline SM8 x SA3 & $1.15 \mathrm{e}-\mathrm{i}$ & $0.52 \mathrm{i}-\mathrm{n}$ & $1.72 \mathrm{f}$ \\
\hline SM8 x SA6 & $1.11 \mathrm{ij}$ & $0.45 \mathrm{j}-\mathrm{n}$ & $1.07 \mathrm{f}$ \\
\hline SM8 x SA8 & $1.14 \mathrm{f}-\mathrm{j}$ & $0.66 \mathrm{~d}-\mathrm{i}$ & $5.08 \mathrm{ef}$ \\
\hline SM8 x SA11 & $1.15 \mathrm{e}-\mathrm{i}$ & $0.59 \mathrm{f}-1$ & $2.68 \mathrm{f}$ \\
\hline SM8 x SA12 & $1.08 \mathrm{j}$ & $0.50 \mathrm{i}-\mathrm{n}$ & $0.00 \mathrm{f}$ \\
\hline SM8 x SA13 & $1.12 \mathrm{~h}-\mathrm{j}$ & $0.61 \mathrm{f}-1$ & $0.00 \mathrm{f}$ \\
\hline SM8 x SA14 & $1.17 \mathrm{c}-\mathrm{i}$ & $0.52 \mathrm{i}-\mathrm{n}$ & $0.70 \mathrm{f}$ \\
\hline SM8 x SA17-1 & $1.21 \mathrm{~b}-\mathrm{e}$ & $0.67 \mathrm{~d}-\mathrm{i}$ & $1.02 \mathrm{f}$ \\
\hline SM9 x SA3 & $1.34 \mathrm{a}$ & $1.00 \mathrm{ab}$ & $0.00 \mathrm{f}$ \\
\hline SM9 x SA12 & $1.19 \mathrm{~b}-\mathrm{g}$ & $0.62 \mathrm{e}-\mathrm{k}$ & $0.00 \mathrm{f}$ \\
\hline SM9 x SA13 & $1.24 \mathrm{~b}$ & $0.50 \mathrm{i}-\mathrm{n}$ & $4.35 \mathrm{ef}$ \\
\hline SM9 x SA17-1 & $1.34 \mathrm{a}$ & $0.64 \mathrm{e}-\mathrm{j}$ & $0.00 \mathrm{f}$ \\
\hline SM9 x SA17-2 & $1.18 \mathrm{~b}-\mathrm{h}$ & $1.17 \mathrm{a}$ & $0.00 \mathrm{f}$ \\
\hline SM11 x SA6 & $1.11 \mathrm{i}-\mathrm{j}$ & $0.59 \mathrm{f}-1$ & $4.69 \mathrm{ef}$ \\
\hline SM11 x SA11 & $1.23 \mathrm{bc}$ & $0.75 \mathrm{c}-\mathrm{h}$ & $0.00 \mathrm{f}$ \\
\hline SM11 x SA17-1 & $1.13 \mathrm{~g}-\mathrm{j}$ & $0.61 \mathrm{f}-1$ & $0.00 \mathrm{f}$ \\
\hline SM12 x SA6 & $1.16 \mathrm{~d}-\mathrm{i}$ & $0.43 \mathrm{k}-\mathrm{n}$ & $1.67 \mathrm{f}$ \\
\hline SM12 x SA8 & $1.15 \mathrm{e}-\mathrm{i}$ & $0.50 \mathrm{i}-\mathrm{n}$ & $0.00 \mathrm{f}$ \\
\hline SM12 x SA11 & $1.13 \mathrm{~g}-\mathrm{j}$ & $0.65 \mathrm{e}-\mathrm{j}$ & $0.00 \mathrm{f}$ \\
\hline SM12 x SA14 & $1.12 \mathrm{~h}-\mathrm{j}$ & $0.411-n$ & $0.00 \mathrm{f}$ \\
\hline SM12 x SA17-1 & $1.13 \mathrm{~g}-\mathrm{j}$ & $0.61 \mathrm{f}-1$ & $18.18 \mathrm{bc}$ \\
\hline SM12 x SA17-2 & $1.12 \mathrm{~h}-\mathrm{j}$ & $0.61 \mathrm{f}-1$ & $5.00 \mathrm{ef}$ \\
\hline $\mathrm{P}$ & 0.01 & 0.01 & 0.01 \\
\hline $\mathrm{CV}(\%)$ & 1.4 & 7.8 & 27 \\
\hline
\end{tabular}


Çalışma sonucunda, türler arası melezlenebilirlik ve meyvedeki tohum sayısı birlikte incelendiğinde; SM8 X SA6, SM6 X SM6 ve SM12 X SA6 kombinasyonlarının ümit var anaç kombinasyonları olduğu belirlenmiştir. Aşılı patlıcan fidesi üretimine yönelik olarak geliştirilen bu yerli anaç adaylarının, gelecekte anaç çeşit ıslah programlarında değerlendirilerek ülke tarımına kazandırılması yönünde çalışmalara devam edilmektedir.

\section{Teşekkür}

$\mathrm{Bu}$ çalışma, SANTEZ / TEYDEB (Proje No: 0832.STZ.2014) tarafindan desteklenen projeden elde edilen verilerle hazırlandığ 1 için, Sanayi ve Teknoloji Bakanlığına ve Tübitak'a maddi desteklerinden dolayı teşekkür ederiz. Ayrıca çalışmanın arazi kısmındaki yardımlarından ötürü, Gento Tohumculuk Tarım Sanayi ve Tic. Ltd. Şti. çalışanlarına da teşekkür ederiz.

\section{Kaynaklar}

Afful, N.T., Nyadanu, D., Akromah, R., Amoatey, H.M., Annor, C., Diawouh, R.G., 2018. Evaluation of crossability studies between selected eggplant accessions with wild relatives $S$. torvum, $S$. anguivi and S. aethiopicum (Shum group). J. Plant Breed. Crop Sci., 10: 1-12.

Ali, M., Fujieda, K., 1990. Cross compatibility between eggplant (Solanum melongena) and wild relatives. J. Jpn. Soc. Hortic. Sci., 58: 977-984.

Balkaya, A., Kandemir, D., Sarıbaş, Ş., 2015. Türkiye sebze fidesi üretimindeki son gelişmeler. TÜRKTOB Türkiye Toh. Bir. Der., 4(13): 4-8.

Balkaya, A., 2014. Aşılı sebze üretiminde kullanılan anaçlar. TÜRKTOB Türkiye Toh. Bir. Der., 3(106): 4-7.

Behera, T.K., Singh, N., 2002. Inter-specific crosses between eggplant (Solanum melongena L.) with related Solanum species. Sci. Hort., 95(1-2): 165172.

Bletsos, F., Roupakias, D., Tsaktsira, M., Scaltsoyjannes, A., 2004. Produc-tion and characterization of interspecific hybrids between three eggplant (Solanum melongena L.) cultivars and Solanum macrocarpon L. Sci. Hort., 101(1-2):1121.

Boyacı, H.F., 2007. Patlıcanlarda Fusarium splgunluğuna dayanıklılık kaynakları ve dayanıklılığın kalıtımı. Doktora Tezi. Çukurova Üniversitesi Fen Bilimleri Enstitüsü, 96s, Adana.

Bremner, P.M., Eckersall, R.N., Scott, R.K., 1963. The relative importance of embryo size and endosperm size in causing the effects associated with seed size in wheat. The Journal of agricultural Science, 61(1): 139-145.

Calvo-Asensio, I., Prohens, J., Gisbert, C., 2014. Vigor for in vitro culture traits in $S$. melongena $\times S$. aethiopicum hybrids with potential as rootstocks for eggplant. Sci. World J. 2014, 1-8.

Collonier, C., Fock, I., Kashyap, V., 2001. Applications of biotechnology in eggplant. Plant Cell Tiss. Org., 65(2): 91-107.

Çürük, S., Dayan, A., 2017. Solanum melongena ve Solanum torvum'un türler arası melezlerinin morfolojik özellikleri. Mediterranean Agricultural Sciences, 30(3): 179-188.

Daunay, M.C., Chaput, M.H., Sihachakr, D., Allot, M., Vedel, F., Ducreux, G., 1993. Production and characterization of fertile somatic hybrids of eggplant (Solanum melongena L.) with Solanum aethiopicum L. Theor. Appl. Genet., 85(6-7): 84185.

Daunay, M.C. 2008. Handbook of Plant Breeding: Vegetables II, Springer, New York, USA, 163-220.

Devi, C.P., Munshi, A.D., Behera, T.K., Choudhary, H., Vinod Gurung, B., Saha, P., 2015. Cross compatibility in interspecific hybridization of eggplant, Solanum melongena, with its wild relatives. Sci. Hort. 193: 353-358.

Fidebirlik, 2016. Fide Üreticileri Alt Birliği. http://www.fidebirlik.org.tr/, (Erişim tarihi: 06 Şubat 2019)

García-Fortea, E., Gramazio, P., Vilanova, S., Fita, A., Mangino, G., Villanueva, G., Arrones, A., Knapp, S., Prohens, J., Plazas, M., 2019. First successful backcrossing towards eggplant (Solanum melongena) of a New World species, the silver leaf nightshade (S. elaeagnifolium), and characterization of interspecific hybrids and backcrosses. Sci. Hort., 246: 563-573.

Gisbert, C., Prohens, J., Nuez F., 2011a. Performance of eggplant grafted on to cultivated, wild, and hybrid materials of eggplant and tomato. Int. J. of Plant Pro., 5(4): 367-380.

Gisbert, C., Prohens, J., Raigon, M.D., Stommel, J.R., Nuez, F., 2011b. Eggplant relatives as sources of variation for developing new rootstocks: Effects of grafting on eggplant yield and fruit apparent quality and composition. Sci. Hort., 128(1): 14-22.

Hayase, H., 1961. Cucurbita crosses: XIII. Utilization of bud pollination in obtaining interspesific hybrids of C. Pepo x C. Maxima. Japanese J. of Breed., 25: 181-190.

Iwamoto, Y., Hirai, M., Ohmido, N., Fukui, K., Ezura, H., 2007. Fertile somatic hybrids between Solanum integrifolium and S. sanitwongsei (sny. S. kurzii) as candidates for bacterial wilt-resistant rootstock of eggplant. Plant Biotechnology, 24: 179-184.

İko, M., Ivani, A., Bohanec, B., 2003. Genome size analysis in the genus Cucurbita and its use for determination of interspecific hybrids obtained using the embryo-rescue technique. Plant Science, 165(3): 663-669.

Kandemir, D., Sarıbaş, H.Ş., Balkaya, A., 2016. Așılı patlıcan üretiminde kullanılan anaçların verim ve 
kalite üzerine etkileri. Tarım Gündem Dergisi, 6(33): 24-28.

Karaağaç, O., Özbakır, M., Balkaya, A., 2011. Barbunya fasulye (Phaseolus vulgaris var. pinto) tohumlarının farklı nem içeriklerinde bazı fiziksel özelliklerinin belirlenmesi. IV. Tohumculuk Kongresi, 14-17 Haziran, Samsun.

Karaağaç, O., 2013. Karadeniz Bölgesinden Toplanan Kestane Kabağ 1 (C. maxima Duchesne) ve Bal Kabağı (C. moschata Duchesne) Genotiplerinin Karpuza Anaçlık Potansiyellerinin Belirlenmesi. Doktora Tezi. Ondokuz Mayıs Üniversitesi Fen Bilimleri Enstitüsü, 238s, Samsun.

Karaağaç, O., Balkaya, A., 2013. Interspecific hybridization and hybrid seed yield of winter squash (Cucurbita maxima Duch.) and pumpkin (Cucurbita moschata Duch.) lines for rootstock breeding. Sci. Hort., 149: 9-12.

King, S., Davis, A.R., Zhang, X., Crosby, K., 2010. Genetics, breeding and selection of rootstocks for Solanaceae and Cucurbitaceae. Sci. Hort., 127(2): 106-111.

Kumchai, J., Wei, Y.C., Lee, C.Y., Chen, F.C., Chin, S.W., 2013. Production of interspecific hybrids between commercial cultivars of the eggplant (Solanum melongena L.) and its wild relative $S$. torvum. Genet. Mol. Res. 12: 755-764.

Nascimento, W.M., Pinheiro, F., Freitas, R.A., 2007. Utilizaço do ethephon para a produço de sementes de hbrido de abbora tipo $t$ etsukabuto (Utilization of 226 ethephon on hybrid seed production of tetsukabu to type squash), Revista Brasileira de Sementes, 29(2): 10-14.

Oda, M., 1999. Grafting of vegetables to improve greenhouse production. Food \& Fertilizer Technology Centre Extension Bulletin, 480: 1-11.

Oyelana, O.A., Ugborogho, R.E., 2008. Phenotypic variation of $\mathrm{F} 1$ and $\mathrm{F} 2$ populations from three species of Solanum L. (Solanaceae). Afr. J. Biotechnol., 7: 2359-2367.

Plazas, M., Vilanova, S., Gramazio, P., RodriguezBurruezo, A., Rajakapasha, R., Ramya, F., Niran, L., Fonseka, H., Kouassi, B., Kouassi, A., Prohens, J., 2016. Interspecific hybridization between eggplant and wild relatives from different genepools. J. Am. Soc. Hort. Sci., 141: 34-44.

Prohens, J., Plazas, M., Raigón, M.D., Seguí-Simarro, J.M., Stommel, J.R., Vilanova, S., 2012. Characterization of interspecific hybrids and first backcross generations from crosses between two cultivated eggplants (S. melongena and $S$. aethiopicum Kumba group) and implications for eggplant breeding. Euphytica, 186: 517-538.

Rao, S.V., Rao, B.G.S., 1984. Studies on the crossability relationships of some spinous Solanum. Theor. Appl. Genet., 67: 419-426.

Rhodes, A.M., 1959. Species hybridization and interspecific gene transfer in the genus, Cucurbita.
Proceeding American Society Horticultural Science, 74: 546-552.

Sakata, Y., Ohara, T., Sugiyama, M., 2007. The history and present state of the grafting of cucurbitaceous vegetables in Japan. Acta Hort, 731: 159-170.

Sihachakr, D., Daunay, M.C., Serraf, I., Chaput, M.H., Mussio, I., Haicour, R., Rossignol, L. Ducreux, G., 1994. Somatic hybridization of eggplant (Solanum melongena L.) with its close and wild relatives. In: Bajaj YPS (ed) Biotechnology in Agriculture and Forestry, Somatic Hybridization in Crop Improvement, Vol I, Springer-Verlag, Berlin, Heidelberg, 255-278.

Tatlioglu, T., 1993. Cucumber (Cucumis sativus L.) In: Kalloo G, Bergh BO. Genetic improvement of vegetable crops. Tarrytown, NY, Pergamon Press, 197-234.

Toppino, L., Vale, G., Rotino, G.L., 2008. Inheritance of Fusarium wilt resistance introgressed from Solanum aethiopicum Gilo and Aculeatum groups into cultivated eggplant (S. melongena) and development of associated PCR-based markers. Molecular Breeding, 22 (2): 237-250.

Whitaker, T.W., Robinson, R.W., 1986. Squash breeding. In: Bassett M.J. (Ed.). Breeding Vegetable Crops. Westport, Connecticut: Avi, 209-242.

Yamaguchi, J., Shiga, T., 1993. Characteristics of regenerated plants via protoplast electrofusion between melon (Cucumis melo) and pumpkin (interspecific hybrid, Cucurbita maxima $\mathrm{x} C$. moschata). Japanese Journal of Breeding, 43: 173-182.

Yamakawa, K., 1982. Use of rootstocks in solanaceous fruit-vegetable production in Japan. Japan Agricultural Research Quarterly, 15: 175-179.

Yılmaz, S., Çelik, İ., Boyacı, F., Yeşilova, Ö., 2005. Aşılı domates fide üretiminde kullanılan Solanum torvum'un Fusarium oxysporium f. $\mathrm{sp}$. melongena'ya karşı reaksiyonları ve anaç performansinın belirlenmesi. II. Tohumculuk Kongresi, 9-11 Kasım, Adana.

Yongan, C., Bingkui, Z., Enhui, Z., Zunlian, Z., 2002a. Study on affinity of sexual hybridization between Cucurbita maxima and Cucurbita moschata. Cucurbit Genetics Cooperative Report, 25: 54-55.

Yongan, C., Bingkui, Z., Enhui, Z., Zunlian, Z., 2002b. Germplasm innovation by interspecific crosses in pumpkin. Cucurbit Genetics Cooperative Report, 25: 56-57. 